
DOI: $10.31866 / 2616-7654.7 .2021 .233297$

ТЕОРЕТИКО-
МЕТОДОЛОГІЧНІ
ЗАСАДИ
ПІДГОТОВКИ ІНТЕРНЕТ-
МАРКЕТОЛОГА
ЗА СПЕЦІАЛЬІСТЮ
029 «ІНФОРМАЦІИНА,
БІБЛІОТЕЧНА
ТА АРХІВНА СПРАВА»

Тетяна Новальська, завідувачка кафедри інформаційних технологій Київского національного університету культури і мистещтв, докторка історичних наук, професорка (Київ, Україна) e-mail: novalska@meta.ua ORCID: 0000-0003-3093-3998

\author{
Владислав Касьян, \\ старший викладач кафедри документознавства \\ та інформаційно-аналітичної діяльності \\ Київського національного університету \\ культури і мистецтв, \\ кандидат філософських наук \\ (Київ, Україна) \\ e-mail:kasjanvv@gmail.com \\ ORCID: 0000-0003-0539-4531
}

Метою статті є обгрунтування теоретико-методологічних засад реалізації освітньої інновації - освітньо-професійної програми «Менеджмент соціально-комунікаційних мереж. Інтернет-маркетинг» за спеціальністю 029 «Інформаційна, бібліотечна та архівна справа».

Методологія дослідження базується на сукупності загальнонаукових методів узагальнення, систематизації і прогнозування. Застосування методу гіпотетичного аналізу дало змогу виявити концептуальні засади теоретико-методологічної платформи підготовки інтернет-маркетолога за спеціальністю 029 «Інформаційна, бібліотечна та архівна справа».

Наукова новизна дослідження полягає у тому, що в умовах динамічного урізноманітнення професійної інформаційної діяльності та пропозицій нових спеціалізацій у межах спеціальності «Інформаційна, бібліотечна та архівна справа» обгрунтовано інноваційний підхід до розробки теоретико-методологічної платформи підготовки інтернет-маркетолога і виявлено основні концепти, які уможливлюють конструювання професійної моделі інтернет-маркетолога за спеціальністю «Інформаційна, бібліотечна та архівна справа». Такими концептами визначено соціально-інформаційні комунікації та управління документно-інформаційними ресурсами (інформаційний менеджмент).

Висновки. Основними концептами теоретико-методологічної платформи освітньої інновації з підготовки інтернет-маркетолога за спеціальністю «Інформаційна, бібліотечна та архівна справа» $€$ соціально-комунікативні технології та управління документно-інформаційними ресурсами (інформаційний менеджмент). Завдання маркетингової діяльності фахівця із соціально-інформаційних комунікацій за спеціальністю 029 «Інформаційна, бібліотечна та архівна справа» відповідають проблемному полю соціально-комунікативної діяльності, охоплюють маркетинг у сфері діяльності некомерційних організацій, державного управління, благодійних організацій, бібліотек, архівів, музеїв та ін. Теоретичний зміст предметної області діяльності інтернет-маркетолога узгоджується зі Стандартом вищої освіти за спеціальністю «Інформаційна, бібліотечна та архівна справа» і відповідає концептуальним основам предметної галузі управління документно-інформаційними ресурсами (інформаційного менеджменту). Запропонований варіант теоретико-методологічної платформи освітньої інновації - підготовки інтернет-маркетолога за спеціальністю «Інформаційна, бібліотечна та архівна справа» - здатний до збагачення, видозміни та уточнення у процесі розвитку наукових знань та емпіричної бази у цій предметній галузі. 
Ключові слова: інтернет-маркетолог, соціально-комунікативні технології, управління документно-інформаційними ресурсами, інформаційний менеджмент, підготовка фахівців, інформаційна, бібліотечна та архівна справа.

\section{ВСТУП}

Підготовка в Україні інформаційних фахівців у рамках спеціальності 029 «нформаційна, бібліотечна та архівна справа» відбувається в умовах прискореної адаптації фаху до технологічних і соціальних змін, спричинених широким впровадженням у суспільну практику інтернет-технологій, і вимагає постійної актуалізації і модернізації освітніх програм із метою забезпечення відповідності суспільним потребам і ринку праці.

Пропозиції нових спеціалізацій та розробка відповідних їм навчальних планів підготовки студентів об'єктивно перебувають на емпіричному етапі розвитку та потребують перманентного коригування окремих елементів. Формування актуальної професіограми є тривалим процесом, що обумовлює невідповідність кадрового забезпечення інформаційної діяльності розвитку інформаційного середовища і потребує прогнозування сутнісних трансформацій інформаційних професій та здійснення випереджальної підготовки фахівця.

Очевидною є суперечність, зумовлена, з одного боку, динамікою професійної різноманітності інформаційної діяльності, пропозиціями спеціалізацій у межах спеціальності, а з іншого - браком педагогіко-прогностичних та моделюючих заходів для окреслення теоретичного базису та функціонального наповнення нових професій і побудови якісного навчального плану підготовки. Необхідність подолання такої суперечності актуалізує потребу обгрунтування теоретико-методологічної платформи (Загвязинський, 2010) розробки моделі фахівця і подальшої побудови та реалізації навчальних планів підготовки, які були б адаптованими до сучасних цифрових технологій та процедур і практик соціально-комунікативної інформаційної діяльності.

У статті сфокусовано увагу на запропонованій у межах спеціальності «Інформаційна, бібліотечна та архівна справа» освітньо-професійній програмі «Менеджмент соціально-комунікаційних мереж. Інтернет-маркетинг», яка $є$ інноваційною не лише за змістом - як відповідь на потреби ринку праці, а й із позиції звичної термінології у назвах спеціалізацій за спеціальністю.

Висунемо гіпотезу щодо релевантності наявного у назві спеціалізації терміна «інтернет-маркетинг» змісту спеціальності «Інформаційна, бібліотечна та архівна справа», виходячи з таких міркувань:

1. Сучасні види діяльності, зокрема й діяльність у галузі соціально-інформаційних комунікацій, до якої відносяться і маркетингові комунікації, характеризуються взаємопроникненням технологій та способів професійної діяльності і потребують фахівця, здатного наповнювати і розвивати інформаційне середовище, застосовуючи відповідні соціально-комунікативні технології.

2. Складова «інформаційна справа» у назві спеціальності передбачає підготовку фахівців для діяльності, в тому числі, й поза межами бібліотечних та архівних установ. Компетентності, які відповідають діяльності фахівця інформаційного профілю для здійснення широкого спектра соціально-інформаційних 
комунікацій, відображені у Стандарті вищої освіти за спеціальністю 029 ("Стандарт вищої освіти України", 2018b).

3. Завдання маркетингової діяльності фахівця із соціально-інформаційних комунікацій (інтернет-маркетолога) за спеціальністю 029 перебувають у проблемному полі соціально-комунікативної діяльності, охоплюють сфери маркетингу у діяльності некомерційних організацій, державного управління, благодійних організацій, бібліотек, архівів, музеїв та ін. Теоретичний зміст предметної області діяльності фахівця визначено як інформаційні та документні системи установ, технології управління інформаційними, архівними та бібліотечними ресурсами. У такому формулюванні предметної області очевидна відмінність від професійної освіти в галузі маркетингу, яка регламентується Стандартом спеціальності 075 Маркетинг, галузь знань 07 Управління та адміністрування ("Стандарт вищої освіти України", 2018а). Цей Стандарт визначає теоретичний зміст предметної області діяльності фахівця, характеризуючи суть маркетингу як сучасну концепцію управління бізнесом.

Необхідність визначення теоретико-методологічного підгрунтя запропонованої освітньої інновації зумовлена потребою розробки професійної моделі фахівця і подальшої побудови концепції підготовки інтернет-маркетолога як основи реалізації навчально-виховного процесу.

Отже, метою статті $є$ обгрунтування теоретико-методологічних засад реалізації освітньої інновації - освітньо-професійної програми «Менеджмент соціально-комунікаційних мереж. Інтернет-маркетинг», спеціальність 029 «Інформаційна, бібліотечна та архівна справа».

\section{МЕТОДИ І МАТЕРІАЛИ}

Теоретико-методологічною основою наукового обгрунтування концептуальних основ розробки моделі фахівця є здобутки педагогічної науки у галузі теорії і методики професійної освіти. Ці напрацювання забезпечують необхідні засади для побудови концепції підготовки фахівців за спеціальністю 029 «Інформаційна, бібліотечна та архівна справа». Методологія дослідження базується на сукупності загальнонаукових методів узагальнення, систематизації і прогнозування. Застосування методів гіпотетичного аналізу і абстрагування дало змогу виявити сутнісні ознаки основних концептів, якими окреслюється теоретико-методологічне підгрунтя підготовки інтернет-маркетолога за спеціальністю 029 «Інформаційна, бібліотечна та архівна справа».

Теоретичні передумови дослідження були закладені в ряді наукових публікацій вітчизняних фахівців, які приділяють посилену увагу питанням трансформації підготовки фахівців за спеціальністю 029 «Інформаційна, бібліотечна та архівна справа».

Так, у статті А. Соляник (2018) представлено інноваційні критерії результативності ступеневої підготовки фахівців зі спеціальності 029 «Інформаційна, бібліотечна та архівна справа» на основі застосування Дублінських дескрипторів як інноваційних критеріїв. Проблема формування комунікаційних компетентностей у студентів вказаної спеціальності стала предметом наукової уваги у статті В. Сошинської (2017). На етапи розвитку та характерні ознаки бібліотечноінформаційної освіти звертає увагу Н. Бачинська (2018), проблеми наступності здобуття вищої бібліотечно-інформаційної та архівної освіти в умовах реформування висвітлюються Т. Новальською (2017). 
Важливі для розвитку наукового бачення підготовки інформаційних фахівців акценти були розставлені А. Гуменчуком (2019), який запропонував модель інтелектуалізації вищої бібліотечно-інформаційної освіти. Дослідник визначає головним орієнтиром її когнітивної модернізації інтелектуалізацію усіх ключових компонентів її змісту - техніко-технологічного, проєктно-аналітичного, дослідно-інноваційного, комунікаційного, аксіологічного (морально-етичного), психолого-педагогічного, організаційно-управлінського.

Безпосередньо до проблем виявлення змісту майбутньої професійної діяльності інформаційного фахівця, на основі якого можна надалі будувати модель його професійної підготовки, звертаються О. Матвієнко та М. Цивін (2016; 2017; 2018). Т. Гранчак (2017) обгрунтовано актуальність і перспективність посилення аналітичного компонента у програмі підготовки бакалаврів інформаційної, бібліотечної та архівної справи.

У контексті предмета дослідження доцільно також звернути увагу на публікацію Л. Іваненко і О. Боєнко (2020), у якій авторки репрезентують розробку моделі професійної підготовки фахівців-маркетологів на основі компетентнісного підходу, виділяючи у ній цільову, методологічну, змістову та результативну складові.

Широке коло проблем, охоплене названими та багатьма іншими авторами, зроблені ними висновки, сформульовані концепції та висловлені пропозиції щодо розвитку спеціальності «Інформаційна, бібліотечна та архівна справа» дають змогу розробити теоретичні та методичні підходи до побудови моделі фахівця за освітньо-професійною програмою «Менеджмент соціально-комунікаційних мереж. Інтернет-маркетинг».

\section{РЕЗУЛЬТАТИ ДОСЛІДЖЕННЯ}

Освітньо-професійна програма «Менеджмент соціально-комунікаційних мереж. Інтернет-маркетинг» $\epsilon$ інноваційною розробкою у межах спеціальності 029 «Інформаційна, бібліотечна та архівна справа», зокрема у частині її складової «інформаційна справа», яка спрямована на задоволення суспільних потреб і ринку праці в умовах прискорених техніко-технологічних та соціально-економічних трансформацій. Пропозиція освітньої програми дає змогу реалізувати підготовку та розвиток професійних кадрів для широкого спектра видів і напрямів інформаційної та соціально-комунікативної діяльності.

Запропонована інновація потребує визначення теоретичних засад (концептуальної бази), на основі яких надалі конструюватиметься професійна модель інтернет-маркетолога, розробки адекватних спеціальності 029 навчальних планів підготовки та засобів діагностування.

Доцільним є виявлення основних концептів підготовки інтернет-маркетолога у контексті соціальних комунікацій, зокрема з урахуванням специфіки прикладних соціально-комунікаційних технологій, предметне поле яких окреслене у наукових публікаціях та у Паспорті наукової спеціальності 27.00 .06 - прикладні соціально-комунікаційні технології ("Паспорт спеціальності 27.00.06", б.р.).

Так, серед визначених Паспортом спеціальності напрямів досліджень, які можуть бути прийняті як опис предметного поля прикладних соціально-комунікативних технологій і стосуються інформаційної та соціально-комунікативної діяльності інтернет-маркетолога, наявні: 
- історія, теорія та методологія формування інформаційних середовищ взаємодії суб’єктів соціальної діяльності;

- соціально-комунікаційні технології позиціювання суб’єктів соціальної діяльності в суспільстві (зв’язки із громадськістю, реклама, іміджмейкінг, бізнес-комунікації тощо);

- комунікаційний образ суб'єктів суспільних відносин;

- використання засобів масової комунікації при здійсненні зв’язків із громадськістю;

- організація діяльності служб та агенцій (зв’язків із громадськістю, рекламних агенцій тощо);

- спеціалізовані PR-технології (політичні, консалтингові, журналістські);

- публічні зв’язки з державними структурами;

- маркетингові комунікації ("Паспорт спеціальності 27.00.06", б.р.).

Окреслений зміст Паспорта спеціальності «прикладні соціально-комунікаційні технології» корелюється із завданнями інтернет-маркетолога як фахівця із соціально-комунікативних технологій, який володіє сукупністю прийомів у сфері соціальних комунікацій, « <..> спрямованих на управління людиною, групами, суспільством і суспільствами в плані налагодження соціальної взаємодії за допомогою передачі соціально значущих знань» (Різун, 2013, с. 22), а тому може бути прийнятий за теоретичну основу концепту підготовки такого фахівця.

У такому ракурсі підготовка інтернет-маркетологів як соціально-комунікативний напрям освіти у межах спеціальності 029 розкриває нові грані, набуває нового сенсу і дає змогу розглядати термін «інтернет-маркетолог» не у площині предметної сфери бізнесу, комерції, продажів і прибутку, а у вимірі інформаційно-комунікативної діяльності, як компонент терміносистеми інформаційного менеджменту та інформаційного маркетингу.

У цьому контексті варто зазначити, що розглянута у статті О. Матвієнко та Д. Дубова (2006) сфера інформаційного некомериійного маркетингу - його структура, цільові групи, мета, стратегії тощо - чітко співвідноситься зі специфікою інтернет-маркетингу, релевантного, насамперед, спеціальності соціально-інформаційного профілю «Інформаційна, бібліотечна та архівна справа». Відокремлюючи при аналізі комерційну складову інформаційного маркетингу, автори зазначають, що його особливість полягає в тому, що «товаром» $є$ ідеї, програми та погляди, спрямовані на максимальне задоволення соціально важливих некомерційних потреб суспільства.

У згаданій статті такі визначені різновиди інформаційного некомерційного маркетингу, як політичний, соціальний, освітній маркетинг, маркетинг території, інформаційний маркетинг країни, які не містять комерційної складової, обгрунтовані як актуальні напрями соціально-інформаційних комунікацій, що охоплюються предметною сферою інтернет-маркетингу з реалізацією завдань добору, аналізу, оцінки, систематизації, моніторингу, організації, зберігання, розповсюдження та надання в користування інформації та знань.

Примітно також, що ці завдання відповідають концепції інформаційного менеджменту, зокрема його структурі, яка включає:

- оперативне використання інформації як стратегічного ресурсу з метою забезпечення конкурентноздатності організації;

- управління процесами опрацювання інформації; 
- використання інформації для цілеспрямованого формування зовнішньої і внутрішньої комунікативної політики організації (Матвієнко \& Цивін, 2018).

Відповідність документно-інформаційних завдань сфери інформаційного менеджменту професійній діяльності інтернет-маркетолога дає змогу стверджувати, що інформаційний менеджмент та його складові - менеджмент знань та менеджмент контенту - можуть розглядатися як теоретичне підгрунтя діяльності інтернет-маркетолога. Ця теза співзвучна із висновками О. Матвієнко та М. Цивіна (Матвієнко \& Цивін, 2017, с. 27; Матвієнко \& Цивін, 2018, с. 66) стосовно концептуалізації моделі фахівця з інформаційної справи на основі інформаційного менеджменту та використання концепту «управління знаннями» як методологічного орієнтира досліджень змісту спеціальності 029 «Інформаційна, бібліотечна та архівна справа».

Отже, ще одним концептом теоретичної платформи підготовки інтернет-маркетолога може бути визначено «управління документно-інформаційними ресурсами» (інформаційний менеджмент).

При цьому основні концепти теоретичної платформи підготовки інтернет-маркетолога мають перебувати у предметному полі спеціальності «Інформаційна, бібліотечна та архівна справа» у взаємоузгодженості із об'єктами вивчення та діяльності майбутнього фахівця та теоретичним змістом предметної області за спеціальністю, яка визначена у Стандарті вищої освіти 029 «Інформаційна, бібліотечна та архівна справа».

Методологічно доцільним у зв'язку з цим є з'ясування відповідності фахових компетентностей, визначених у Стандарті вищої освіти за спеціальністю 029, виявленим концептам теоретичної платформи підготовки інтернет-маркетолога, якими є соціально-комунікативні технології та управління документно-інформаційними ресурсами.

Зазначимо, що представлені компетентності чітко не розмежовуються за визначеними складовими функціональної спеціалізації, натомість утворюючи системне «компетентнісне поле» фахівця у визначеному Стандартом теоретичному змісті предметної області та об’єкті діяльності:

1) соціально-комунікативні технології:

- здатність використовувати PR та інші прикладні соціокомунікаційні технології в умовах сучасної інформаційно-технологічної інфраструктури;

- $\quad$ здатність підтримувати ділову комунікацію з усіма суб’єктами інформаційного ринку, користувачами, партнерами, органами влади та управління, засобами масової інформації;

- здатність аналізувати закономірності розвитку, документно-інформаційних потоків та масивів, як штучно створеної підсистеми соціальних комунікацій;

- здатність створювати, наповнювати та забезпечувати функціонування веб-сайтів та веб-спільнот у мережі інтернет;

- $\quad$ здатність адмініструвати соціальні мережі, електронні бібліотеки та архіви.

2) управління документно-інформаційними ресурсами:

- здатність здійснювати відбір, аналіз, оцінку, систематизацію, моніторинг, організацію, зберігання, розповсюдження та надання в користування інформації та знань у будь-яких форматах;

- здатність використовувати методи систематизації, пошуку, збереження, класифікації інформації для різних типів контенту та носіїв; 
Український журнал з бібліотекознавства та інформаційних наук. Випуск 7 (2021) Ukrainian Journal on Library and Information Science. Issue 7 (2021)

- здатність проєктувати та створювати документно-інформаційні ресурси, продукти та послуги.

Наявні у Стандарті компетентності та їх співвіднесення з основними концептами підготовки інтернет-маркетолога спонукають звернутися до вимог ринку праці до завдань діяльності таких фахівців. Більшість роботодавців слушно вважають інтернет-маркетолога фахівцем, який просуває бренд в інтернеті, і поміж завдань його діяльності виділяють:

- управління рекламними кампаніями та PR-акціями у мережі;

- моніторинг галузі, в якій відбувається просування товару (послуги);

- звіти та презентує рекомендації із просування товару (послуги) керівництву організації;

- аналіз статистики, KPI сайту (кількість трафіку та його джерела, показники «клікабельності» (англ. Click-through rate, CTR) - співвідношення кількості показів посилань і кількості натискувань на вказане посилання) та соціальних мереж;

- управління репутацією у мережі інтернет (Search Engine Reputation Management, SERM та Online Reputation Management. ORM), заходи з пошукової оптимізації сайту (Search Engine Optimization, SEO ) та маркетинг у соціальних мережах (Social Media Marketing, SMM );

- $\quad$ розробку стратегії для різних каналів комунікації та ін.

Значна увага з боку роботодавців приділяється роботі у команді, управлінню проєктами та персоналом, що є складником сучасних професіограм представників багатьох видів діяльності, зокрема й за спеціальністю 029 «Інформаційна, бібліотечна та архівна справа». Загалом ці та інші вимоги відображаються у навчальних планах підготовки та у змісті відповідних навчальних дисциплін.

У професійній спільноті інтернет-маркетологів дискутується питання стосовно того, чи повинен інтернет-маркетолог бути програмістом. Більшість роботодавців не бачать у цьому необхідності, отже постає питання про систему цифрових компетентностей фахівця як необхідного складника професіограми. У цьому контексті слушною є думка, висловлена А. Гуменчуком (2020), який, досліджуючи систему цифрових компетентностей фахівця за спеціальністю «Інформаційна, бібліотечна та архівна справа», наголошує, що в умовах цифрової економіки важливими є компетентності, які забезпечують гнучкість та адаптивність фахівця до нових викликів і вимог цифровізації, постійний саморозвиток і здатність навчатися впродовж життя. Зважаючи на прискорені темпи інноваційного розвитку інформаційних технологій і постійне оновлення програмно-технологічного забезпечення діяльності інформаційних фахівців, бачиться недоцільною жорстка регламентація в освітній програмі конкретних знань і умінь інтернет-маркетолога в галузі програмного забезпечення та комп’ютерних технологій, водночас при побудові освітньої програми доцільно керуватися викладеними вище міркуваннями.

\section{ВИСНОВКИ}

Основними концептами теоретико-методологічної платформи освітньої інновації з підготовки інтернет-маркетолога за спеціальністю «Інформаційна, бібліотечна та архівна справа» $€$ соціально-комунікативні технології та управління документно-інформаційними ресурсами (інформаційний менеджмент). 
Завдання маркетингової діяльності фахівця із соціально-інформаційних комунікацій за спеціальністю 029 «Інформаційна, бібліотечна та архівна справа» перебувають у проблемному полі соціально-комунікативної діяльності, охоплюють маркетинг у сфері діяльності некомерційних організацій, державного управління, благодійних організацій, бібліотек, архівів, музеїв та ін. Теоретичний зміст предметної області діяльності інтернет-маркетолога узгоджується зі Стандартом вищої освіти за спеціальністю «Інформаційна, бібліотечна та архівна справа» і відповідає концептуальним основам предметної галузі управління документно-інформаційними ресурсами (інформаційного менеджменту).

Запропонований варіант теоретико-методологічної платформи освітньої інновації - підготовки інтернет-маркетолога за спеціальністю «Інформаційна, бібліотечна та архівна справа» - здатний до збагачення, видозміни та уточнення, тобто трансформації контенту у процесі розвитку наукових знань та накопичення емпіричної бази у цій предметній галузі.

\section{СПИСОК ПОСИЛАНЬ}

Бачинська Н. А. Бібліотечно-інформаційна освіта в Україні: етапи розвитку та характерні ознаки. Бібліотекознавство. Документознавство. Інформологія. 2018. № 3. С. 57-67.

Гранчак Т. Ю. Дисципліни аналітичного профілю як компонент програми підготовки бакалаврів зі спеціальності «Інформаційна, бібліотечна та архівна справа». Наукові праці Національної бібліотеки України імені В. І. Вернадського. 2017. Вип. 46. С. 117-128.

Гуменчук А. В. Модель інтелектуалізації вищої бібліотечно-інформаційної освіти. Вісник Харківської державної академії культури. 2019. Вип. 55. С. 70-81.

Гуменчук А. Система цифрових компетентностей Бібліотекаря 4.0. Вісник Книжкової палати. 2020. № 2. С. 23-28.

Загвязинский В. И. Исследовательская деятельность педагога. 3-е изд., стер. Москва : Издательский центр «Академия», 2010. 176 с.

Іваненко Л. М., Боєнко О. Ю. Розробка моделі професійної підготовки фахівців-маркетологів на основі компетентнісного підходу. Бізнес Інформ. 2020. № 5. С. 492-502. URL: https://cutt.ly/XcWxTsT (дата звернення: 5.04.2021).

Матвієнко О. В. Основи інформаційного менеджменту : навч. посіб. Київ : Центр навчальної літератури, 2004. 128 с.

Матвієнко О. В., Дубов Д. В. Інформаційний маркетинг у контексті державних, політичних та соціальних інформаційних відносин. Вісник Книжкової палати. 2006. № 3. С. 33-36.

Матвієнко О., Цивін М. Інформаційний менеджмент як основа концептуалізації моделі фахівця з інформаційної справи. Вісник Книжкової палати. 2017. № 4. С. 27-30.

Матвієнко О., Цивін М. Спеціальність 029 «Інформаційна. бібліотечна та архівна справа»: у пошуках «інформаційного фахівця». Вісник Книжкової палати. 2016. № 10. С. 32-35.

Матвієнко О. В., Цивін М. Н. «Управління знаннями» як методологічний орієнтир пошуку концепту спеціальності «Інформаційна, бібліотечна та архівна справа». Український журнал з бібліотекознавства та інформаційних наук. 2018. № 2. С. 66-76.

Новальська Т. В. Наступність здобуття вищої бібліотечно-інформаційної та архівної освіти в умовах реформування. Бібліотекознавство. Документознавство. Інформологія. 2017. № 1. С. 4-10.

Паспорт спеціальності 27.00.06 - прикладні соціально-комунікаційні технології.URL:http:// asp.univ.kiev.ua/doc/Pasport/27.00.00/27.00.06.pdf (дата звернення: 5.04.2021). 
Різун В. В. До питання про соціально комунікаційні наукові проблеми і про наукові проблеми взагалі. Актуальні дослідження українських наукових шкіл у галузі соціальних комунікацій : матеріали Всеукр. наук.-практ. конф. / наук. ред. В. Різун ; упоряд. Т. Скотникова ; Ін-т журналістики КНУ ім. Т. Шевченка. Київ, 2013. С. 8-25.

Соляник А. А. Інноваційні критерії результативності ступеневої підготовки фахівців зі спеціальності 029 «Інформаційна, бібліотечна та архівна справа». Український журнал з бібліотекознавства та інформаційних наук. 2018. № 1. С. 64-75.

Сошинська В. Формування комунікаційних компетенцій у студентів спеціальності 029 «Інформаційна, бібліотечна та архівна справа» Інституту журналістики Київського університету імені Бориса Грінченка. Інтегровані комунікації. 2017. № 4. С. 56-57.

Стандарт вищої освіти України: перший (бакалаврський) рівень, галузь знань 07 Управління та адміністрування, спеціальність 075 - «Маркетинг»: затверджено і введено в дію Наказом Міністерства освіти і науки України від 05.12.2018 р. № 1343. URL: https://cutt.ly/GcWxxrh (дата звернення: 5.04.2021).

Стандарт вищої освіти України: перший (бакалаврський) рівень, галузь знань 02 Культура і мистецтво, спеціальність 029 «Інформаційна, бібліотечна та архівна справа» : затверджено і введено в дію Наказом Міністерства освіти і науки України від 12.12.2018 p. № 1378. URL: https://cutt.ly/3zSKrGH (дата звернення: 5.04.2021).

\section{REFERENCES}

Bachynska, N. A. (2018). Bibliotechno-informatsiina osvita v Ukraini: etapy rozvytku ta kharakterni oznaky [Library and information education in Ukraine: stages of development and characteristics]. Library Science. Record Studies. Informology, 3, 57-67 [in Ukrainian].

Hranchak, T. Yu. (2017). Dystsypliny analitychnoho profiliu yak komponent prohramy pidhotovky bakalavriv zi spetsialnosti "Informatsiyna, bibliotechna ta arkhivna sprava" [Disciplines of the Analytical Profile as a Component of the Bachelor's Degree Program "Information, Library and Archive Science"]. Academic Papers of Vernadsky National Library of Ukraine, 46, 117-128 [in Ukrainian].

Humenchuk, A. V. (2019). Model intelektualizatsii vyshchoi bibliotechno-informatsiynoi osvity [Model of intellectualization of higher library and information education]. Visnyk of Kharkiv State Academy of Culture, 55, 70-81 [in Ukrainian].

Humenchuk, A. (2020). Systema tsyfrovykh kompetentnostei Bibliotekari 4.0 [The system of digital competencies of the Librarian 4.0]. Bulletin of the Book Chambe, 2, 23-28 [in Ukrainian].

Zagvyazinskiy, V. I. (2010). Issledovatel'skaya deyatel'nost' pedagoga [Research activities of the teacher] (3rd ed.). Publishing House "Academia" [in Russian].

Ivanenko, L. M., \& Boienko, O. Yu. (2020). Rozrobka modeli profesiinoi pidhotovky fakhivtsivmarketolohiv na osnovi kompetentnisnoho pidkhodu [Development of a model of professional training of marketing specialists based on the competence approach]. Biznes Inform, 5, 492-502. https://cutt.ly/XcWxTsT [in Ukrainian].

Matviienko, O. V. (2004). Osnovy informatsiinoho menedzhmentu [Fundamentals of information management]. Tsentr navchalnoi literatury [in Ukrainian].

Matviienko, O. V., \& Dubov, D. V. (2006). Informatsiinyi marketynh u konteksti derzhavnykh, politychnykh ta sotsialnykh informatsiinykh vidnosyn[Information marketing in the context of state, political and social information relations]. Bulletin of the Book Chambe, 3, 33-36 [in Ukrainian].

Matviienko, O., \& Tsyvin, M. (2017). Informatsiinyi menedzhment yak osnova kontseptualizatsii modeli fakhivtsia $\mathrm{z}$ informatsiinoi spravy [Information management as a basis for 
conceptualization of the model of an information specialist]. Bulletin of the Book Chambe, 4, 27-30 [in Ukrainian].

Matviienko, O., \& Tsyvin, M. (2016). Spetsialnist 029 "Informatsiina. bibliotechna ta arkhivna sprava": u poshukakh "informatsiinoho fakhivtsia" [Specialty 029 "Information, Library and Archival Affairs": in search of "information specialist"]. Bulletin of the Book Chambe, 10, 32-35 [in Ukrainian].

Matviienko, O. V., \& Tsyvin, M. N. (2018). "Upravlinnia znanniamy" yak metodolohichnyi oriientyr poshuku kontseptu spetsialnosti "Informatsiina, bibliotechna ta arkhivna sprava" ["Knowledge Management" as a methodological guideline for finding the concept of the specialty "Information, Library and Archival Affairs"]. Ukrainian Journal on Library and Information Science, 2, 66-76 [in Ukrainian].

Novalska, T. V. (2017). Nastupnist zdobuttia vyshchoi bibliotechno-informatsiino ta arkhivnoi osvity v umovakh reformuvannia [Continuity of obtaining higher library and information and archival education in the conditions of reform]. Library Science. Record Studies. Informology, 1, 4-10. [in Ukrainian].

Pasport spetsialnosti 27.00.06 - prykladni sotsialno-komunikatsiini tekhnolohii [Passport of specialty 27.00.06 - applied social and communication technologies]. (n.d.). Retrived March 5, 2021, from https://cutt.ly/7bIJ7TX [in Ukrainian].

Rizun, V. V. (2013). Do pytannia pro sotsialno komunikatsiini naukovi problemy i pro naukovi problemy vzahali [On the question of social communication scientific problems and scientific problems in general]. In V. Rizun (Ed.), \& T. Skotnikova (Comp.), Aktualni doslidzhennia ukrainskykh naukovykh shkil u haluzi sotsialnykh komunikatsii [Current Research of Ukrainian Scientific Schools in the Field of Social Communications], Proceedings of the all-Ukrainian Scientific and Practical Conference (pp. 8-25). Kyiv, Ukraine. Institute of Journalism of Taras Shevchenko National University of Kyiv [in Ukrainian].

Solianyk, A. A. (2018). Innovatsiini kryterii rezultatyvnosti stupenevoi pidhotovky fakhivtsiv zi spetsialnosti 029 "Informatsiyna, bibliotechna ta arkhivna sprava" [Innovative criteria for the effectiveness of degree training of specialists in the specialty 029 "Information, Library and Archival Affairs"]. Ukrainian Journal on Library and Information Science, 1, 64-75 [in Ukrainian].

Soshynska, V. (2017). Formuvannia komunikatsiinykh kompetentsii u studentiv spetsialnosti 029 "Informatsiina, bibliotechna ta arkhivna sprava" Instytutu zhurnalistyky Kyivskoho universytetu imeni Borysa Hrinchenka [Formations Students' Communication Skills on the Specialty 029 "Information, Library and Archive Sciences" of Institute of Journalism of Borys Hrinchenko Kyiv University]. Integrated communications, 4, 56-57 [in Ukrainian].

Ministry of Education and Science of Ukraine. (2018a). Standart vyshchoi osvity Ukrainy: pershyi (bakalavrskyi) riven, haluz znan 07 Upravlinnia ta administruvannia, spetsialnist 075 "Marketynh" [Standard of higher education of Ukraine: first (bachelor's) level, field of knowledge 07 Management and administration, specialty 075 - "Marketing"]: Approved and put into effect by the Order of the Ministry of Education and Science of Ukraine dated 05.12.2018 N 1343. https://cutt.ly/GcWxxrh [in Ukrainian].

Ministry of Education and Science of Ukraine. (2018b). Standart vyshchoi osvity Ukrainy: pershyi (bakalavrskyi) riven, haluz znan 02 Kultura i mystetstvo, spetsialnist 029 "Informatsiina, bibliotechna ta arkhivna sprava" [Standard of higher education of Ukraine: first (bachelor's) level, field of knowledge 02 Culture and art, specialty 029 "Information, Library and Archival Affairs": Approved and put into effect by the Order of the Ministry of Education and Science of Ukraine dated 12.12.2018 N 1378. https://cutt.ly/3zSKrGH [in Ukrainian]. 
UDC 02+930.25]:378.013.3+[004.738.5:339.138]:378.016:[005:001.102+004.77:316.77]

\author{
Tetyana Novalska, \\ Head of the Information \\ Technology Department \\ at the Kyiv National University \\ of Culture and Arts, \\ Dr. Hab. in Historical Sciences, Professor \\ (Kyiv, Ukraine) \\ e-mail:novalska@meta.ua \\ ORCID: 0000-0003-3093-3998 \\ Vladislav Kasian, \\ Senior Lecturer of the Department \\ of the Document Science, Information \\ and Analytical Activities \\ at the Kyiv National University \\ of Culture and Arts, Ph.D. \\ in Philosophical Sciences \\ (Kyiv, Ukraine) \\ e-mail:kasjanvv@gmail.com \\ ORCID: 0000-0003-0539-4531
}

\title{
THEORETICAL AND METHODOLOGICAL FUNDAMENTALS OF INTERNET MARKETING TRAINING IN SPECIALTY 029 "INFORMATION, LIBRARY AND ARCHIVAL AFFAIRS"
}

The purpose of the article is to substantiate the theoretical and methodological foundations of educational innovation which is educational and professional program «Management of social and communication networks. Digital marketing», specialty 029 «Information, Library and Archival Affairs».

The research methodology is based on a set of general scientific methods of generalization, systematization and forecasting. Hypothetical analysis made it possible to develop to identify the basic concepts that outline the theoretical and methodological platform for training Digital marketers in the specialty «Information, Library and Archival Affairs».

The scientific noveltyof the study is that in the dynamics of professional diversity of information activities and proposals for new specializations within the specialty «Information, Library and Archival Affairs» outlines the main approaches to the theoretical and methodological platform for Digital marketers and identifies basic concepts that allow building a professional model of Digital marketer in the specialty 029 «Information, Library and Archival Affairs». Such concepts define social and information communications and management of document and information resources (information management).

Conclusions. The main concepts of the theoretical and methodological platform of educational innovation for the training of Digital marketers in the specialty «Information, Library and Archival Affairs» are social and communication technologies and management of document and information resources (information management). Tasks of marketing activities of a specialist in social information communications in the specialty 029 «Information, Library and Archival Affairs» are in the problem field of social communication activities, include marketing in the field of nonprofit organizations, government, charities, libraries, archives, museums, etc. The theoretical content of the subject area of Internet marketing is consistent with the Standard of Higher Education in «Information, Library and Archival Affairs» and corresponds to the conceptual foundations of the subject area of management of document and information resources (information management). The proposed version of the theoretical 
and methodological platform of educational innovation - training of Digital marketers in the specialty «Information, Library and Archival Affairs» - is able to enrich, modify and refine in the development of scientific knowledge and empirical base in this subject area.

Keywords: Digital marketer, social and communication technologies, management of document and information resources, information management, training, information, library and archival affairs.

Стаття надійшла до редакції 30.03.2021 р. 